\title{
Índice de sustentabilidade para municípios (ISM): um estudo no Estado da Paraíba, Brasil
}

\section{Alexandre de Araújo Gomes Júnior¹, Maria de Fátima Martins $^{2}$ e Edvan Cruz Aguiar ${ }^{2}$}

${ }^{1}$ Escola de Administração de Empresas de São Paulo. Fundação Getúlio Vargas. Avenida Nove de Julho, 2029. Bela Vista. São Paulo-SP, Brasil (CEP 01313-902). E-mail: alexandre.junior1994@gmail.com.

${ }^{2}$ Universidade Federal de Campina Grande. Programa de Pós-Graduação em Administração. Rua Aprígio Veloso, 882. Bodocongó. Campus Universitário. Campina Grande-PB, Brasil (CEP 58428-830).

Resumo. Objetivo deste estudo foi analisar o nível de sustentabilidade dos municípios que compõem a terceira Região Geoadministrativa da Paraíba, Brasil. Para tanto, fundamentou-se na literatura sobre sustentabilidade, desenvolvimento sustentável e índices e indicadores de sustentabilidade. Este é um estudo quantitativo, caracterizado como levantamento cujo recorte é transversal, os dados são secundários e a coleta foi feita por meio de pesquisa documental. Utilizou-se dois sistemas de indicadores para a construção do índice de sustentabilidade para municípios (ISM). Os dados foram submetidos a um teste de correlação (Alpha de Cronbach) no software RStudio para verificar a confiabilidade do modelo. Os resultados apontaram que maioria dos municípios analisados está em nível crítico de sustentabilidade na dimensão econômica; em nível de alerta na dimensão social; em níveis aceitáveis e de alerta na dimensão ambiental; em nível de alerta na dimensão institucional; em nível aceitável na dimensão demográfica; e em nível crítico na dimensão cultural. Em relação ao índice de sustentabilidade agregado, constatou-se que o nível de sustentabilidade é de alerta. Este estudo se diferencia na medida em que utiliza indicadores de dois índices de sustentabilidade próprios para municípios para a construção do ISM. Contribui-se para a literatura na medida em que apresenta um índice de sustentabilidade para municípios. No nível prático, entende-se que os resultados contribuem para lançar luz sobre a situação dos municípios analisados em relação à sustentabilidade e, dessa forma, guiar a formulação de políticas públicas e investimentos no sentido do desenvolvimento sustentável.

Palavras-chave: Índices de sustentabilidade; Desenvolvimento sustentável; Indicadores de sustentabilidade; Gestão municipal.

Abstract. Sustainability index for municipalities (SIM): A study in the State of Paraíba, Brazil. The aim of this paper was to
Recebido

$28 / 04 / 2021$

Aceito

30/05/2021

Disponível on line

$31 / 05 / 2021$

Publicado

31/08/2021

Acesso aberto

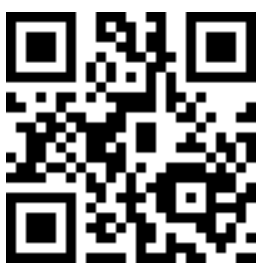

ORCID

D 0000-0002-5665-9715 Alexandre de Araújo Gomes Júnior

(D) 0000-0002-9578-9555

Maria de Fátima

Martins

(D) 0000-0002-3433-6210

Edvan Cruz Aguiar

ISSN 2359-1412/RBGAS-2021-0042/2021/8/19/6/739

Rev. Bras. Gest. Amb. Sustent.

http://revista.ecogestaobrasil.net 
analyze the level of sustainability of the municipalities in the third Geo-Administrative Region of Paraíba, Brazil. It was based on the literature on sustainability, sustainable development and sustainability indexes and indicators. This is a quantitative study, characterized as a survey whose cut is transversal, the data are secondary, and the collection was made through documentary research. Two systems of indicators were used to build the sustainability index for municipalities (SIM). The data were submitted to a correlation test (Cronbach's alpha) in the RStudio software to verify the model's reliability. The results showed that most of the municipalities analyzed are at a critical level of sustainability in the economic dimension; at the level of alertness in the social dimension; at acceptable and alert levels in the environmental dimension; at the level of alertness in the institutional dimension; at an acceptable level in the demographic dimension; and at a critical level in the cultural dimension. In relation to the aggregate sustainability index, it was found that the level of sustainability is alert. This study differs in that it uses indicators from two sustainability indexes specific to municipalities for the construction of the SIM, and contributes to the literature as it presents a sustainability index for municipalities. At the practical level, it is understood that the results contribute to shed light on the situation of the municipalities analyzed in relation to sustainability and, in this way, guide the formulation of public policies and investments towards sustainable development.

Keywords: Sustainability indexes; Sustainable development; Sustainability indicators; Municipal management.

\section{Introdução}

O desenvolvimento dos municípios, dos estados, dos países ou do planeta não pode ser entendido como mero reflexo de crescimento econômico. Aspectos sociais e ambientais devem ser levados em conta para que se considere um sistema desenvolvido. Além disso, deve-se atentar para a noção de continuidade desses sistemas, isto é, a possibilidade de eles se manterem indefinidamente. Foi nesse sentido, que emergiu a concepção de desenvolvimento sustentável, aquele que ultrapassa as barreiras dos aspectos econômicos para dar importância às questões sociais e ambientais que permeiam as sociedades humanas da atualidade, sem esquecer-se das que estão por vir.

É nesse sentido que Abramovay (2012) afirma que o mundo necessita de uma nova economia, pois há aumento de desigualdade na renda, no uso de energia, nas emissões, no consumo, na educação e na saúde, ao mesmo tempo que a produção continua aumentando. $\mathrm{Ou}$ seja, crescimento econômico não é sinônimo de desenvolvimento. O Brasil, por exemplo, é conhecido como um dos países mais desiguais do mundo (Sotomayor 2019). Assim, com o objetivo de enfrentar os problemas sociais e ambientais mais urgentes que a sociedade enfrenta na atualidade, a Organização das Nações Unidas (ONU) lançou em 2015, como uma estrutura política global, os Objetivos do Desenvolvimento Sustentável (ODS) - Agenda 2030 (Bengtsson et al. 2018). 
Os ODS são uma maneira de operacionalizar o desenvolvimento sustentável, que como é um processo, foi e está sujeito a monitoramento e medição por meio de indicadores selecionados de acordo com as metas a serem alcançadas (Cornescu e Adam, 2014). Mais: alcançar esse tipo de desenvolvimento depende, evidentemente, de escolhas da sociedade, das organizações, das comunidades e dos indivíduos (van Bellen 2010). E isso está acontecendo, visto que, um número crescente de governos, empresas e indivíduos estão se preocupando mais com a necessidade de harmonizar os aspectos sociais, econômicos e ambientais (Cornescu e Adam, 2014).

Assim, é importante destacar que, dada a complexidade do desenvolvimento sustentável, os indicadores que buscam analisá-lo consigam captar as questões relevantes para esse processo e descrevam de maneira clara uma realidade mutável, dinâmica e diversa (Martins e Cândido, 2012). Dessa forma, por analogia, os índices formados a partir desses indicadores poderão ser realmente úteis para a avaliação do desenvolvimento sustentável. Isso é significativo, pois os índices oferecem aos tomadores de decisão elementos necessários para avaliação de regiões (Silva et al. 2018), por exemplo.

Diante disso, o objetivo deste estudo foi analisar o nível de sustentabilidade dos municípios que compõem a terceira Região Geoadministrativa da Paraíba. Essa região é formada por 39 municípios, e Campina Grande, segundo município mais populoso do estado, capitaneia-a. Para atingi-lo, optou-se pela realização de um estudo quantitativo, realizado com dados secundários. Apesar da quantidade de sistemas de indicadores de sustentabilidade, eles estão direcionados para países, o que faz com que haja carência de indicadores para municípios (Martins e Cândido, 2012). Por isso, optou-se por realizar essa análise utilizando indicadores de dois sistemas que analisam o desenvolvimento sustentável em municípios, o de Martins e Cândido (2008) e o de Silva et al. (2018).

\section{Desenvolvimento sustentável}

As discussões sobre o que significa desenvolvimento e qual a melhor forma de medi-lo são, em parte, resultados das reflexões acerca da crise no relacionamento entre a sociedade e o meio ambiente, que alcançou importância global a partir da década de 1970 (van Bellen, 2010). Antes disso, o entendimento dominante era de que desenvolvimento era sinônimo de crescimento econômico (Candido et al., 2018). Essa perspectiva separa o meio ambiente das questões socioeconômicas, isto é, os recursos naturais são tidos como externos à humanidade, que os usa e os explora (Hopwood et al., 2005). No entanto, um aumento da conscientização por parte de governos, da sociedade civil e do mercado sobre problemas ambientais fez com que o conceito de desenvolvimento sustentável emergisse (Du Pisani, 2006; van Bellen, 2010).

De acordo com Mitcham (1995), a perspectiva teórica do desenvolvimento sustentável tem origem numa interpretação pós-moderna da História, que considera a existência de limites para o progresso e está fortemente associada ao livro The Limits to Growth (Meadows et al. 1972). Porém, segundo o mesmo autor (1995), as discussões acabaram mudando de direção, e no lugar de serem discutidos "limites", passou-se a debater o "desenvolvimento sustentável", como demonstram os relatórios World Conservation Strategy (IUCN e WWF, 1980) e Our Common Future (Brundtland 1987). Nesse sentido, esse tipo de desenvolvimento foi definido no Relatório Brundtland como "aquele que atende as necessidades do presente sem comprometer a possibilidade de as gerações futuras atenderem as suas próprias necessidades" (CMMAD, 1991, p. 46). Percebe-se que essa é uma definição bastante ampla e, por isso, suscetível a diversas interpretações.

Além disso, a complexidade nas interações entre os sistemas sociais e os sistemas ambientais faz com que o debate sobre desenvolvimento sustentável seja amplo e multidisciplinar, além de possuir particularidades que dificultam sua aplicabilidade 
(Martins e Cândido, 2012). Mais: o uso, a construção e a manutenção sustentáveis de recursos integrados e raros são estabelecidos pelo nível de desenvolvimento tecnológico e organização social (Wojewnik-Filipkowska e Węgrzyn, 2019). Diante disso, o aprofundamento das discussões sobre os reais significados teórico e prático do desenvolvimento sustentável deixaram como um dos resultados a avaliação desse processo por meio de dimensões (van Bellen, 2010).

Normalmente, as dimensões básicas do desenvolvimento sustentável são três: social, econômica e ambiental; no Relatório Brundtland, além dessas, foi adotada a institucional, mas elas podem ser inúmeras (Carvalho e Barcellos, 2009). Sob essa perspectiva das dimensões, para se buscar o desenvolvimento sustentável é necessário entender que elas estão interligadas, são complexas e se influenciam mutuamente (Martins e Cândido, 2012; Silva et al., 2018). Nesse sentido, desde a introdução do conceito de desenvolvimento sustentável na década de 1980, houve uma evolução no sentido de dar mais precisão a ele em termos quantitativos, por isso a necessidade de uma ampla gama de indicadores (Moldan et al., 2012).

Assim, com o objetivo de mensurar a sustentabilidade, indicadores são fundamentais para alcançar o desenvolvimento sustentável (Martins e Cândido, 2012), já que podem influenciar políticas de estado, especialmente quando se baseiam num monitoramento sistemático, quando são comparáveis, quando são utilizados por atores sociais respeitados e quando são amplamente divulgados (Kelley e Simmons, 2015). Mas existem aspectos negativos relativos aos indicadores, pois quando se pretende descrever uma temática ampla, como é o caso do desenvolvimento sustentável, a seleção de indicadores representativos é difícil, informações podem ser perdidas e dados podem ser manipulados (Cornescu e Adam, 2014).

Além disso, é importante destacar que há certa confusão em relação aos significados dos termos indicadores e índices, que por vezes, de forma errada, são utilizados como sinônimos. Indicadores são parâmetros selecionados para refletir as condições do sistema que está sob análise, já os índices são valores agregados formados por indicadores e/ou por outros índices (Siche et al. 2007). Entre os benefícios gerados pelos índices, destacam-se a capacidade de resumir informações, o que facilita a comparação e a avaliação, e a pressão que eles exercem sobre governos e instituições para eles questionarem seus padrões (Becker et al. 2017).

\section{Índices de sustentabilidade}

Índices são instrumentos populares utilizados para avaliar fenômenos complexos como por exemplo sustentabilidade, corrupção percebida, inovação e competitividade, e são empregados em muitos propósitos como acompanhamento de políticas, comunicação ao público e construção de rankings (Becker et al., 2017). Especificamente com foco na sustentabilidade do desenvolvimento é possível citar Human Development Index (UNDP 1995), o Genuine Progress Indicator (Talberth et al., 2007), o Index of Sustainable Economic Welfare (Chelli et al., 2013), o City Development Index (Singh et al., 2009), o Ecological footprint (Wackernagel e Rees, 1998), o Barometer of sustainability (Prescott-Allen 1995), o Índice de Desenvolvimento Sustentável para Municípios (IDSM) (Martins e Cândido, 2008) e o Índice de Desenvolvimento Sustentável (IDS) proposto por (Silva et al. 2018).

o Human Development Index foi desenvolvido pelo Programa das Nações Unidas para o Desenvolvimento e é formado por uma média de três elementos: longevidade, conhecimento e acesso aos recursos básicos (UNDP, 1995). 0 Genuine Progress Indicator é um indicador que surgiu como alternativa ao PIB (Produto Interno Bruto), ele é projetado para medir o bem-estar econômico sustentável, em vez da atividade econômica de forma isolada, pois diferencia a atividade econômica que reduz os capitais social e natural das que aprimoram (Talberth et al., 2007). O Index of Sustainable Economic Welfare, proposto 
em 1989, permite a integração de medidas tradicionais de desempenho econômico com informações sobre aspectos sociais e ambientais (Chelli et al., 2013).

o City Development Index é um índice composto por cinco indicadores em duas dimensões: infraestrutura (domicílios com acesso à água limpa, canalização, eletricidade e telefonia) e esgoto (esgoto não tratado no total de águas e disposição de resíduos sólidos) (Singh et al., 2009). O Ecological Footprint (Pegada Ecológica) é uma ferramenta que permite estimar o consumo de recursos e a assimilação de resíduos de uma população em termos de uma área produtiva correspondente (Wackernagel e Rees, 1998). 0 Barometer of Sustainability (Barômetro da Sustentabilidade) é um método para avaliar e comunicar o progresso de uma localidade rumo à sustentabilidade que combina as dimensões social e ambiental (Prescott-Allen, 1995).

O Índice de Desenvolvimento Sustentável para Municípios (IDSM) é um sistema de indicadores de sustentabilidade voltado para a avaliação de territórios composto por seis dimensões de desenvolvimento sustentável, a saber social, demográfica, econômica, político-institucional, ambiental e cultural (Martins e Cândido, 2008). Com o IDSM é possível obter os índices de desenvolvimento sustentável para cada uma das dimensões do território analisado, como também o índice geral de desenvolvimento sustentável. 0 Índice de Desenvolvimento Sustentável (IDS) também é um índice de sustentabilidade voltado para territórios, que é composto por quatro dimensões: social, ambiental, econômica e institucional (Silva et al., 2018).

Diante do exposto, percebe-se a variedade existente de índices para avaliar o desenvolvimento sustentável. Isso é um reflexo do próprio conceito de desenvolvimento sustentável que abrange muitas questões e dimensões (van Bellen, 2010). Nesse sentido, pode-se afirmar que a elaboração de índices de sustentabilidade é um processo complexo. Assim, Feil e Schreiber (2017) apontam as seguintes etapas para a construção de um índice de sustentabilidade, que devem contar com rigor metodológico, $1^{\text {a }}$ seleção de

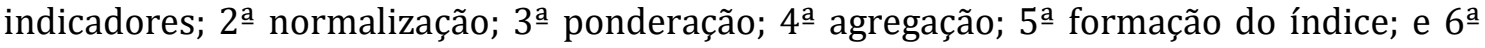
análise de sensibilidade e incerteza.

\section{Metodologia}

\section{Caracterização da pesquisa e seleção dos indicadores}

Esta é uma pesquisa quantitativa, que é uma maneira de testar teorias examinando relações entre variáveis (Creswell, 2010). Além disso, ela é caracterizada com um levantamento cujo propósito foi analisar o nível de sustentabilidade dos municípios que compõem a terceira Região Geoadministrativa da Paraíba. 0 recorte deste levantamento é transversal, os dados são secundários, dos quais a coleta foi feita por meio de pesquisa documental. Entre as vantagens desse tipo de pesquisa estão a parcimônia do modelo e o processo ágil de coleta de dados (Creswell, 2010).

Foram utilizados dados econômicos, sociais, demográficos, ambientais e institucionais dos trinta e nove municípios que compõem a terceira Região Geoadministrativa do Estado da Paraíba (Figura 1), são eles Alagoa Grande, Alagoa Nova, Alcantil, Algodão de Jandaíra, Arara, Areia, Areial, Aroeiras, Assunção, Barra de Santana, Barra de São Miguel, Boa Vista, Boqueirão, Cabaceiras, Campina Grande, Caturité, Esperança, Fagundes, Gado Bravo, Juazeirinho, Lagoa Seca, Livramento, Massaranduba, Matinhas, Montadas, Natuba, Olivedos, Pocinhos, Puxinanã, Queimadas, Remígio, Riacho de Santo Antônio, Santa Cecília, São Domingos do Cariri, São Sebastião de Lagoa de Roça, Soledade, Taperoá, Tenório e Umbuzeiro. 


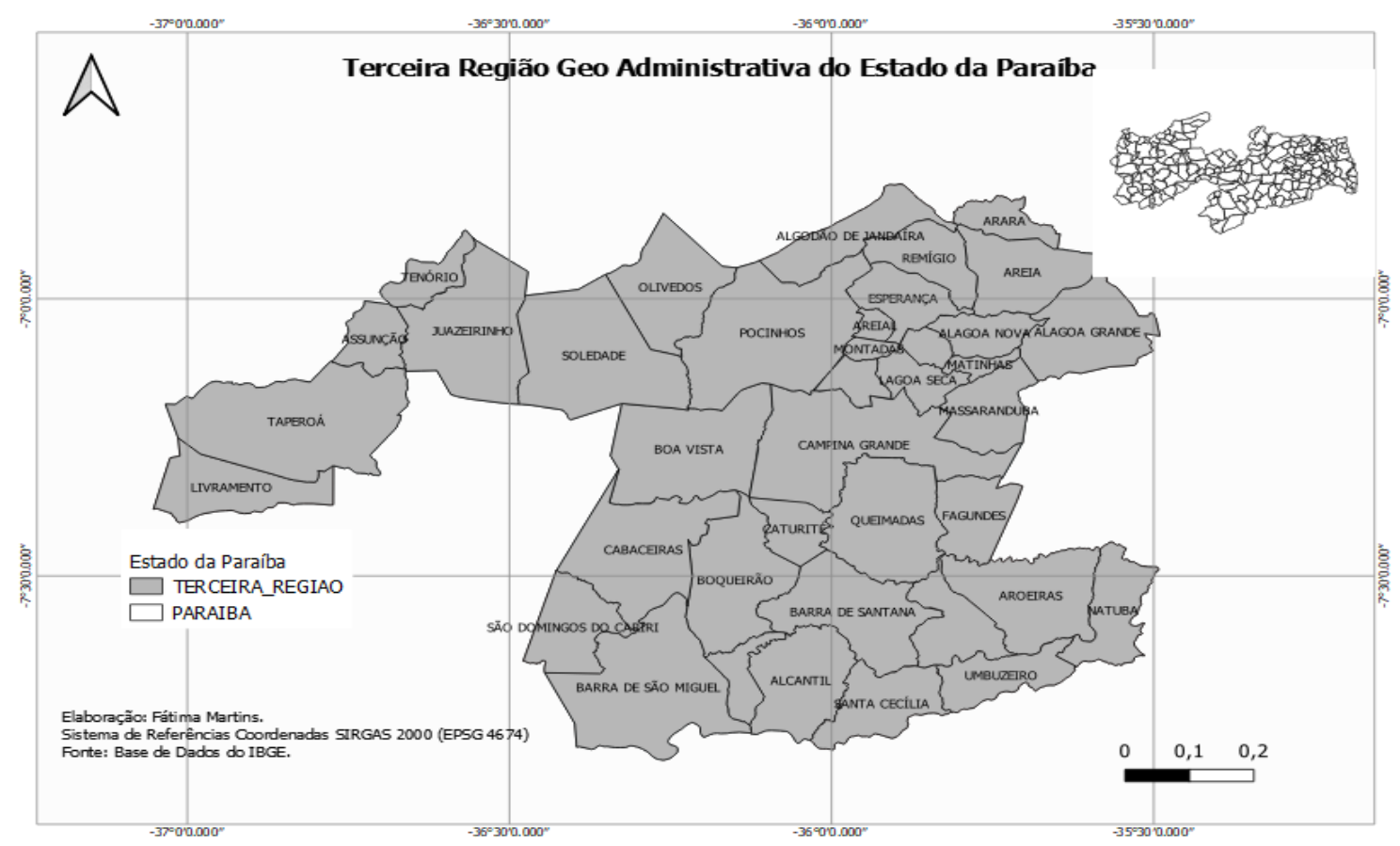

Figura 1. Terceira Região Geoadministrativa da Paraíba.

Os dados dos indicadores dos municípios que foram coletados estavam disponíveis em endereços eletrônicos do Instituto Brasileiro de Geografia e Estatística (IBGE), do Atlas do Desenvolvimento Humano no Brasil, do Ministério da Saúde, do Ministério da Cidadania, do Ministério do Desenvolvimento Regional, do Ministério da Economia, do Instituto Nacional de Pesquisas Espaciais, do Tesouro Nacional, do Tribunal Superior Eleitoral, do Tribunal de Contas do Estado da Paraíba e da Agência Executiva de Gestão das águas (AESA).

Os indicadores utilizados para a construção do índice de Desenvolvimento Sustentável de Municípios deste estudo foram extraídos de dois índices de desenvolvimento sustentável, o elaborado por (Martins e Cândido, 2008) e o desenvolvido por (Silva et al., 2018). É importante destacar que alguns indicadores foram adaptados para a construção do índice proposto neste estudo. 0 modelo apresentado aqui é formado por seis dimensões (econômica, social, ambiental, institucional, demográfica e cultural) e conta com oitenta e cinco indicadores. A Tabela 1 apresenta esses indicadores em suas respectivas dimensões e as fontes dos dados.

Tabela 1. Indicadores utilizados para a construção do Índice de Desenvolvimento Sustentável de Municípios.

\begin{tabular}{|l|l|}
\hline \multicolumn{2}{|c|}{ DIMENSÃO ECONÔMICA } \\
\hline Indicador & Fonte \\
\hline PIB per capita & IBGE (2016) \\
\hline Saldo da balança comercial & Ministério da Economia (2019) \\
\hline Participação da indústria no PIB & IBGE (2016) \\
\hline Participação dos serviços no PIB & IBGE (2016) \\
\hline Receita tributária do município & TCPB (2018) \\
\hline
\end{tabular}


Tabela 1. Continuação.

\begin{tabular}{|c|c|}
\hline \multicolumn{2}{|l|}{ DIMENSÃO ECONÔMICA } \\
\hline Transferências correntes & TCPB (2018) \\
\hline Domicílios com acesso à energia elétrica & IBGE (2010) \\
\hline Renda per capita & IBGE (2010) \\
\hline Índice de Gini de Distribuição de rendimento & MS (2010) \\
\hline Renda proveniente do trabalho & PNUD (2010) \\
\hline Salário médio dos trabalhadores formais & IBGE (2017) \\
\hline População ocupada & IBGE (2017) \\
\hline \multicolumn{2}{|l|}{ DIMENSÃO SOCIAL } \\
\hline Indicador & Fonte \\
\hline Esperança de vida ao nascer & PNUD (2010) \\
\hline Mortalidade infantil & IBGE (2017) \\
\hline Prevalência da desnutrição total & MS (2010) \\
\hline Cobertura Poliomielite & MS (2018) \\
\hline Cobertura Sarampo & MS (2018) \\
\hline Crianças nascidas com quantidade adequada de pré-natais. & MS (2018) \\
\hline Procedimentos básicos de saúde & MS (2018) \\
\hline Postos de trabalho médico & MS (2019) \\
\hline Leitos hospitalares & MS (2019) \\
\hline Estabelecimentos de saúde & MS (2019) \\
\hline Mortalidade por agressão & MS (2017) \\
\hline Mortalidade por acidentes de transporte & MS (2017) \\
\hline Taxa de alfabetização & IBGE (2010) \\
\hline Taxa de escolarização de 0 a 5 anos & PNUD (2010) \\
\hline Taxa de escolarização de 6 a 14 anos & PNUD (2010) \\
\hline Taxa de escolarização de 15 a 17 anos & PNUD (2010) \\
\hline Taxa de escolarização 18 a 24 anos & PNUD (2010) \\
\hline Taxa de analfabetismo (15 anos ou mais) & PNUD (2010) \\
\hline População com ensino superior (25 anos ou mais) & PNUD (2010) \\
\hline IDEB anos iniciais & IBGE (2017) \\
\hline IDEB anos finais & IBGE (2017) \\
\hline População atendida pelo bolsa família & Ministério da Cidadania (2019) \\
\hline População extremamente pobre & PNUD (2010) \\
\hline População com renda familiar até $1 / 2$ de salário mínimo & IBGE (2010) \\
\hline $\begin{array}{l}\text { População com renda familiar com renda de mais de } 1 / 2 \text { até } 1 \\
\text { salário mínimo }\end{array}$ & IBGE (2010) \\
\hline $\begin{array}{l}\text { População com renda familiar com renda de mais de } 1 \text { até } 2 \\
\text { salários mínimos }\end{array}$ & IBGE (2010) \\
\hline População com renda familiar de mais de 2 salários mínimos & IBGE (2010) \\
\hline População atendida com abastecimento de água & MDR (2017) \\
\hline \multicolumn{2}{|l|}{ DIMENSÃO AMBIENTAL } \\
\hline Indicador & Fonte \\
\hline Conformidade da quantidade de amostras de cloro residual & MDR (2017) \\
\hline Incidência das análises de cloro residual fora do padrão & MDR (2017) \\
\hline Conformidade da quantidade de amostras de turbidez & MDR (2017) \\
\hline Incidência das análises de turbidez fora do padrão & MDR (2017) \\
\hline Conformidade da quantidade de amostras de coliformes totais & MDR (2017) \\
\hline Incidência das análises de coliformes totais fora do padrão & MDR (2017) \\
\hline Tratamento da água em ETA's & MDR (2017) \\
\hline Consumo médio per capita de água & MDR (2017) \\
\hline Esgotamento sanitário adequado & IBGE (2010) \\
\hline Precipitação observada & AESA (2018) \\
\hline
\end{tabular}


Tabela 1. Continuação.

\begin{tabular}{|c|c|}
\hline \multicolumn{2}{|c|}{ DIMENSÃO AMBIENTAL } \\
\hline Climatologia & AESA (2018) \\
\hline Volume dos reservatórios de água & AESA (2018) \\
\hline Domicílios com acesso à coleta de lixo & IBGE (2010) \\
\hline Área plantada & IBGE (2018) \\
\hline Risco de fogo & INPE (2018) \\
\hline Arborização das vias públicas & IBGE (2010) \\
\hline Quantidade de veículos & IBGE (2018) \\
\hline \multicolumn{2}{|c|}{ DIMENSÃO INSTITUCIONAL } \\
\hline Indicador & Fonte \\
\hline Despesas com assistência social & Ministério da Economia (2018) \\
\hline Despesas com educação & Ministério da Economia (2018) \\
\hline Despesas com cultura & Ministério da Economia (2018) \\
\hline Despesas com urbanismo & Ministério da Economia (2018) \\
\hline Despesas com habitação & Ministério da Economia (2018) \\
\hline \multicolumn{2}{|c|}{ DIMENSÃO INSTITUCIONAL } \\
\hline Indicador & Fonte \\
\hline Despesas com gestão ambiental & Ministério da Economia (2018) \\
\hline Despesas com ciência e tecnologia & Ministério da Economia (2018) \\
\hline Despesas com desporto e lazer & Ministério da Economia (2018) \\
\hline Despesas com saneamento & Ministério da Economia (2018) \\
\hline Despesas com saúde & Ministério da Economia (2018) \\
\hline Participação nas eleições & TSE (2018) \\
\hline Taxa de eleitores analfabetos & TSE (2018) \\
\hline Taxa dos eleitores que leem e escrevem & TSE (2018) \\
\hline Quantidade de conselhos municipais & IBGE (2018) \\
\hline \multicolumn{2}{|c|}{ DIMENSÃO DEMOGRÁFICA } \\
\hline Indicador & Fonte \\
\hline Densidade demográfica & IBGE (2019) \\
\hline Taxa de crescimento da população & IBGE $(2010,2019)$ \\
\hline Razão entre as populações urbana e rural & IBGE (2010) \\
\hline Razão entre as populações masculina e feminina & IBGE (2010) \\
\hline Taxa da população até 14 anos & IBGE (2010) \\
\hline Taxa da população de 15 a 59 anos & IBGE (2010) \\
\hline Taxa da população com 60 anos ou mais & IBGE (2010) \\
\hline \multicolumn{2}{|c|}{ DIMENSÃO CULTURAL } \\
\hline Indicador & Fonte \\
\hline Quantidade de bibliotecas & IBGE (2018) \\
\hline Quantidade de museus & IBGE (2018) \\
\hline Quantidade de ginásios de esporte e estádios & IBGE (2018) \\
\hline Quantidade de cinemas & IBGE (2018) \\
\hline Quantidade de unidades de ensino superior & IBGE (2018) \\
\hline Quantidade de teatros ou salas de espetáculos & IBGE (2018) \\
\hline Quantidade de centros culturais & IBGE (2018) \\
\hline
\end{tabular}

Fonte: Martins e Cândido (2008) e Silva et al. (2018).

Após a coleta de dados dos indicadores apresentados na Tabela 1, eles foram submetidos a um processo de normalização, isto é, as variáveis foram colocadas numa escala que varia de zero a um, conforme o proposto por (Martins e Cândido, 2008). As fórmulas para normalização foram as seguintes: 
Se a relação for positiva:

$$
\mathrm{I}=(\mathrm{x}-\mathrm{m}) /(\mathrm{M}-\mathrm{m})
$$

Se a relação for negativa:

$$
\mathrm{I}=(\mathrm{M}-\mathrm{x}) /(\mathrm{M}-\mathrm{m})
$$

Nas quais, "I" representa o valor do indicador, " $\mathrm{x}$ " representa o valor da variável bruto, "M" representa o maior valor encontrado na variável e " $m$ " representa o menor valor encontrado na variável. A relação do indicador é positiva em relação a sustentabilidade quando quanto maior for o valor do indicador, melhor para o processo de desenvolvimento sustentável. A relação do indicador é negativa em relação à sustentabilidade quando quanto maior for o valor do indicador, pior para o processo de desenvolvimento sustentável.

Após esse processo de normalização, a base de dados composta pelos oitenta e cinco indicadores divididos em seis dimensões foi submetida a um processo de limpeza, no qual os indicadores que tinham quatro ou mais observações faltantes foram retirados. Seguindo, os indicadores, por dimensões, foram submetidos a um teste de correlação (Alpha de Cronbach) no software RStudio para verificar a confiabilidade do modelo do Índice de Sustentabilidade para Municípios.

A etapa seguinte foi a dos cálculos dos índices de desenvolvimento sustentável por dimensão e do índice geral de desenvolvimento sustentável dos municípios analisados neste estudo. Esses cálculos foram feitos por meio de média aritmética. Para análise dos índices de desenvolvimento sustentável, os municípios foram classificados conforme propõem Martins e Cândido (2008). Essa classificação está presente na Tabela 2.

Tabela 2. Classificação do nível de desenvolvimento sustentável.

\begin{tabular}{|c|c|c|}
\hline Valor do índice & Nível de sustentabilidade & Legenda \\
\hline $0,0000-0,2500$ & Crítico & \\
\hline $0,2501-0,5000$ & Alerta & \\
\hline $0,5001-0,7500$ & Aceitável & \\
\hline $0,7501-1,000$ & Ideal & \\
\hline
\end{tabular}

Fonte: Martins e Cândido (2008).

A partir dessa classificação foram elaborados os resultados quanto ao nível de sustentabilidade dos municípios que compõem a terceira Região Geoadministrativa do Estado da Paraíba.

\section{Resultados e discussão}

\section{Construção do sistema de indicadores}

A análise estatística dos dados foi iniciada com a retirada de indicadores cuja quantidade de observações ausentes era igual ou superior a quatro. Com isso, os seguintes 
indicadores foram removidos: "Saldo da balança comercial", "Mortalidade infantil", "Conformidade da quantidade de amostras de cloro residual", "Incidência das análises de cloro residual fora do padrão", "Conformidade da quantidade de amostras de turbidez", "Incidência das análises de turbidez fora do padrão", "Conformidade da quantidade de amostras de coliformes totais", "Incidência das análises de coliformes totais fora do padrão", "Consumo médio per capita de água", "Climatologia" e "Volume dos reservatórios de água". Ao fim dessa etapa, restaram setenta e três indicadores distribuídos nas seis dimensões.

Seguindo, os indicadores foram submetidos a teste de correlação (Alpha de Cronbach) no software RStudio. Para isso, eles foram testados obedecendo suas respectivas dimensões. Assim, da dimensão econômica foram retirados os seguintes indicadores que não estavam tão bem correlacionados com os demais: "Domicílios com acesso à energia elétrica", "Índice de Gini de Distribuição de rendimento" e "Salário médio dos trabalhadores formais". Da dimensão social, foram retirados "Prevalência da desnutrição total", "Cobertura Poliomielite", "Cobertura Sarampo", "Crianças nascidas com quantidade adequada de pré-natais", "Procedimentos básicos de saúde", "Estabelecimentos de saúde", "Mortalidade por agressão", "Mortalidade por acidentes de transporte", "Taxa de escolarização de 6 a 14 anos", "Taxa de escolarização 18 a 24 anos", "IDEB anos iniciais" e "População com renda familiar com renda de mais de $1 / 2$ até 1 salário-mínimo".

Da dimensão ambiental foram retirados os seguintes indicadores: "Tratamento da água em ETA's", "Precipitação observada", "Área plantada", "Risco de fogo", "Arborização das vias públicas", "Quantidade de veículos". Da dimensão institucional, estes indicadores foram excluídos: "Despesas com assistência social", "Despesas com educação", "Despesas com cultura", "Despesas com urbanismo", "Despesas com gestão ambiental", "Despesas com ciência e tecnologia", "Despesas com desporto e lazer", "Despesas com saúde", "Participação nas eleições" e "Quantidade de conselhos municipais".

Da dimensão demográfica, foram retirados "Taxa de crescimento da população", "Razão entre as populações urbana e rural", "Taxa da população de 15 a 59 anos", "Taxa da população com 60 anos ou mais". Da dimensão cultural, foram excluídos o indicador "Quantidade de bibliotecas". As medidas do teste de correlação (Alpha de Cronbach) por dimensão estão presentes na Tabela 3.

Tabela 3. Teste de correlação.

\begin{tabular}{|l|c|c|c|c|c|c|}
\hline Dimensão & Econômica & Social & Ambiental & Institucional & Demográfica & Cultural \\
\hline Alpha de Cronbach & 0,90 & 0,90 & 0,84 & 0,74 & 0,59 & 0,67 \\
\hline
\end{tabular}

Na Tabela 3, pode-se observar uma forte correlação entre os indicadores que compõem as dimensões econômica, social, ambiental e institucional. Todos os valores do Alpha de Cronbach delas foram superiores a 0,70, o que indica a confiabilidade do modelo nessas dimensões. Na dimensão demográfica, entende-se que houve uma correlação marginal entre os indicadores dessa dimensão. Já na dimensão cultural, pode-se dizer que há uma correlação boa já que o Alpha de Cronbach está muito próximo de 0,70. Os indicadores utilizados para a compor o índice de sustentabilidade dos municípios que compõem a terceira região Geoadministrativa da Paraíba estão presentes na Tabela 4. 
Tabela 4. Indicadores do Índice de Desenvolvimento Sustentável de Municípios.

\begin{tabular}{|l|}
\hline \multicolumn{1}{|c|}{ INDICADORES POR DIMENSÃO } \\
\hline DIMENSÃO ECONÔMICA \\
\hline PIB per capita \\
\hline Participação da indústria no PIB \\
\hline Participação dos serviços no PIB \\
\hline Receita tributária do município \\
\hline Transferências correntes \\
\hline Renda per capita \\
\hline Renda proveniente do trabalho \\
\hline População ocupada \\
\hline \\
\hline Esperança de vida ao nascer \\
\hline Postos de trabalho médico \\
\hline Leitos hospitalares \\
\hline Taxa de alfabetização \\
\hline Taxa de escolarização de 0 a 5 anos \\
\hline Taxa de escolarização de 15 a 17 \\
\hline Taxa de analfabetismo (15 anos ou mais) \\
\hline População com ensino superior (25 anos ou mais) \\
\hline IDEB anos finais \\
\hline População atendida pelo bolsa família \\
\hline População extremamente pobre \\
\hline População com renda familiar até 1/2 de salário mínimo \\
\hline População com renda familiar com renda de mais de 1 até 2 salários mínimos \\
\hline População com renda familiar de mais de 2 salários mínimos \\
\hline População atendida com abastecimento de água \\
\hline \\
\hline Esgotamento sanitário adequado \\
\hline Domicílios com acesso à coleta de lixo \\
\hline DIMENSÃO AMBIENTAL \\
\hline Despesas com habitação \\
\hline Despesas com saneamento \\
\hline Taxa de eleitores analfabetos \\
\hline Taxa dos eleitores que leem e escrevem \\
\hline DIMENSÃO DEMOGRÁFICA \\
\hline Densidade demográfica \\
\hline Razão entre as populaç̃os masculina e feminina \\
\hline Taxa da população até 14 anos \\
\hline Quantidade de museus \\
\hline Quantidade de ginásios de esporte e estádios \\
\hline Quantidade de cinemas \\
\hline Quantidade de teatros ou salas de espetáculos \\
\hline Quantidade de centros culturais \\
\hline
\end{tabular}

Fonte: Martins e Cândido (2008) e Silva et al. (2018).

A próxima fase desta pesquisa consiste em descrever os índices de desenvolvimento sustentável dos municípios que compõem a terceira região Geoadministrativa da Paraíba. Para isso, foram realizados os cálculos dos índices para cada uma das seis dimensões, que consistiram na média aritmética dos indicadores 
presentes no Tabela 3. Posteriormente, foi calculado o índice de desenvolvimento sustentável para cada um dos municípios, ele é formado pela média aritmética dos índices das seis dimensões que compõem o modelo presente no Tabela 4.

\section{Análise dos índices de desenvolvimento sustentável dos municípios da terceira Região Geoadministrativa da Paraíba}

Agora serão analisados os índices desenvolvimento sustentável dos municípios que compõem a terceira região Geoadministrativa da Paraíba. Primeiramente, os índices por dimensão do desenvolvimento sustentável são descritos. Depois, o índice agregado de desenvolvimento sustentável. A primeira análise será da dimensão econômica.

A Figura 2 apresenta o índice de desenvolvimento sustentável dos municípios que forma a Terceira Região Geoadministrativa da Paraíba para a dimensão econômica. É possível constatar que a maior parte (aproximadamente, 72\%) dos municípios apresenta um nível crítico de sustentabilidade. Esse é um aspecto negativo para o processo rumo à sustentabilidade, porque indica que a maioria dos municípios dessa região Geoadministrativa tem uma atividade econômica subdesenvolvida. Cerca de $23 \%$ dos municípios apresentam nível de alerta de sustentabilidade. Isso revela uma situação um pouco melhor, mas deve-se destacar são índices que estão bastante próximos do limite de nível crítico. Apenas o Município de Boa Vista tem nível aceitável de sustentabilidade, e Campina Grande é o único que tem nível ideal de sustentabilidade (aproximadamente, $0,94)$, isso indica que este município tem características econômicas bastante diferentes dos outros que compõem sua região geoadministrativa.

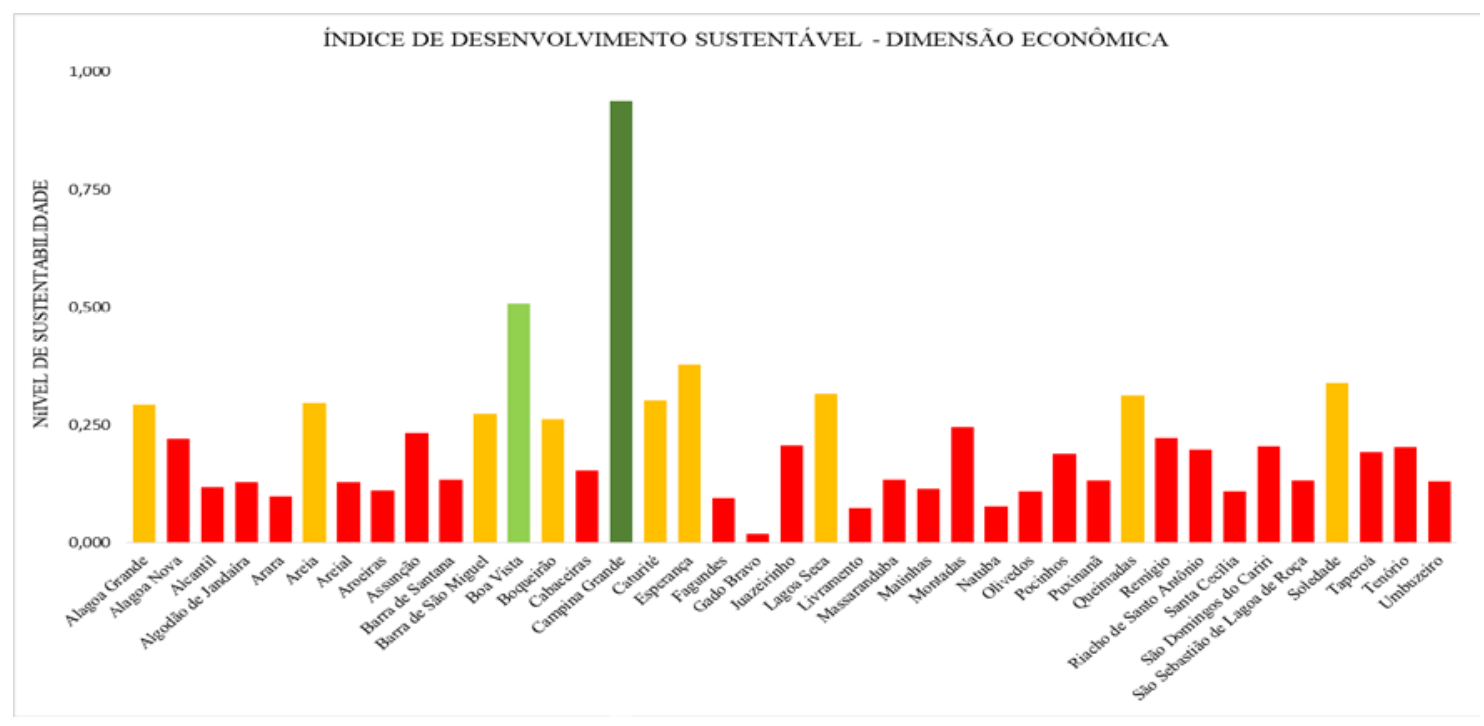

Figura 2. Índice de desenvolvimento sustentável - dimensão econômica.

Os índices de desenvolvimento sustentável para a dimensão social dos municípios em análise estão representados na Figura 3. Pode-se observar que a maioria (cerca de $74 \%$ ) dos municípios está em um nível alerta de sustentabilidade. Esse é um dado que revela deficiências em saúde, educação e equidade nesses municípios. Mas há ainda seis municípios que estão com nível crítico de sustentabilidade, ou seja, em uma situação ainda pior nessa dimensão. Por outro lado, três municípios apresentam nível aceitável de sustentabilidade e apenas Campina Grande é o único município com nível de 
sustentabilidade ideal (cerca de 0,93). Esses dados são preocupantes, pois não há desenvolvimento sustentável sem considerar os aspectos sociais, a melhoria de vida das populações.

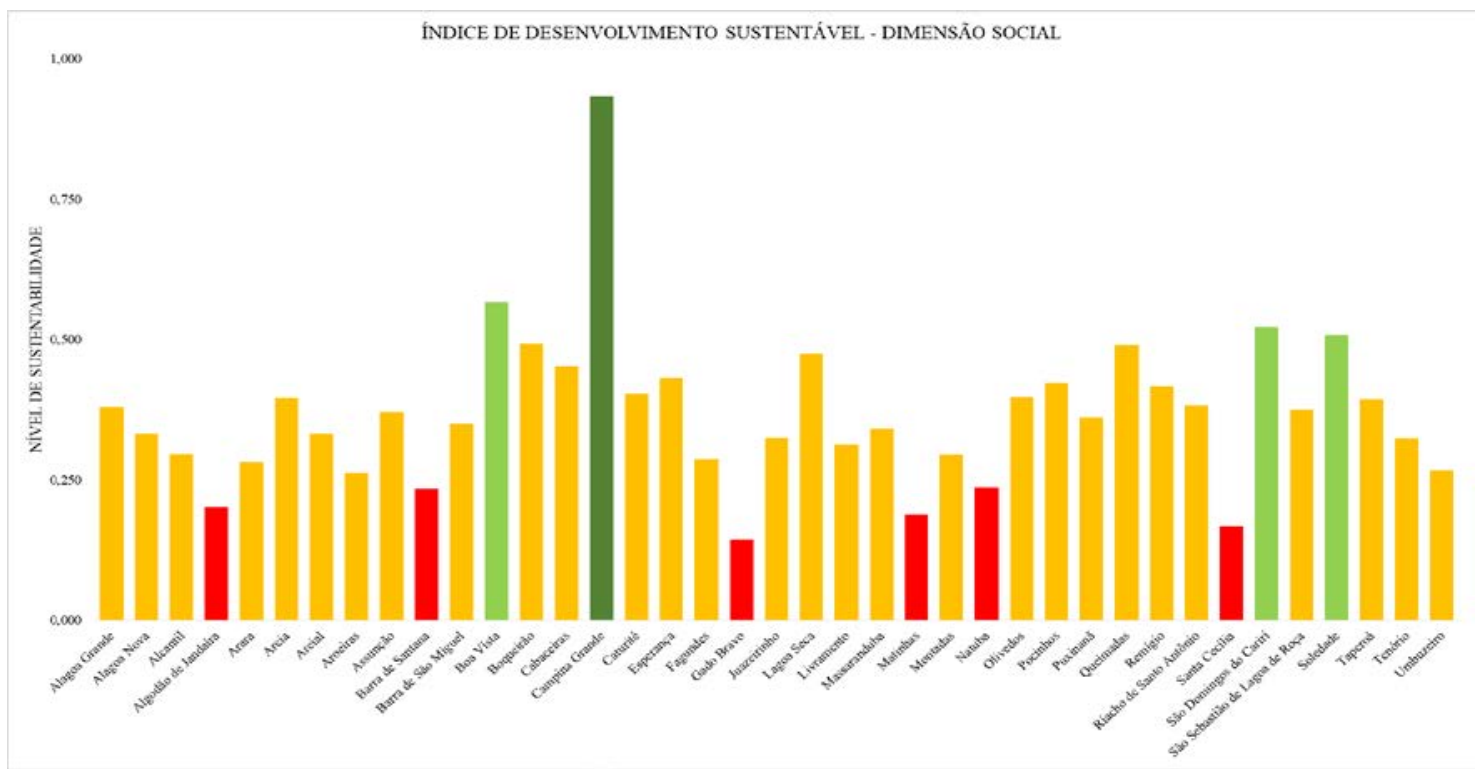

Figura 3. Índice de desenvolvimento sustentável - dimensão social.

Com relação aos índices de desenvolvimento sustentável para a dimensão ambiental por município, cujos dados estão na Figura 4, constata-se que cerca de $38 \%$ dos municípios estão num nível aceitável de sustentabilidade. 0 que é bastante positivo para o desenvolvimento sustentável. Outros 38\% dos municípios estão em nível de alerta. Cinco municípios estão com nível crítico, e outros quatro com nível ideal de sustentabilidade. Cuidar dos aspectos ambientais é fator preponderante para o desenvolvimento sustentável, já que os recursos naturais são finitos. Nessa dimensão, pode-se observar um certo equilíbrio entre a quantidade de municípios que estão em situação melhor para o desenvolvimento sustentável. Esse resultado não evidencia as questões ambientais em sua totalidade, pois com a filtragem dos indicadores, apenas dois puderam ser utilizados na análise.

Os índices de desenvolvimento sustentável para dimensão institucional por município estão na Figura 5. A existência e atuação das instituições é fundamental para a identificação e desenvolvimento das potencialidades dos municípios. Com os resultados da pesquisa, contata-se que cerca de $49 \%$ dos municípios estão em nível de alerta para desenvolvimento sustentável e aproximadamente $45 \%$ dos municípios estão em nível crítico para desenvolvimento sustentável. Esses dados revelam uma situação em que há certo distanciamento do desenvolvimento sustentável na dimensão institucional para a maioria dos municípios da Terceira Região Geoadministrativa da Paraíba. Apenas os Municípios de Campina Grande e Olivedos estão em uma situação aceitável e São Domingos do Cariri está numa situação ideal. 


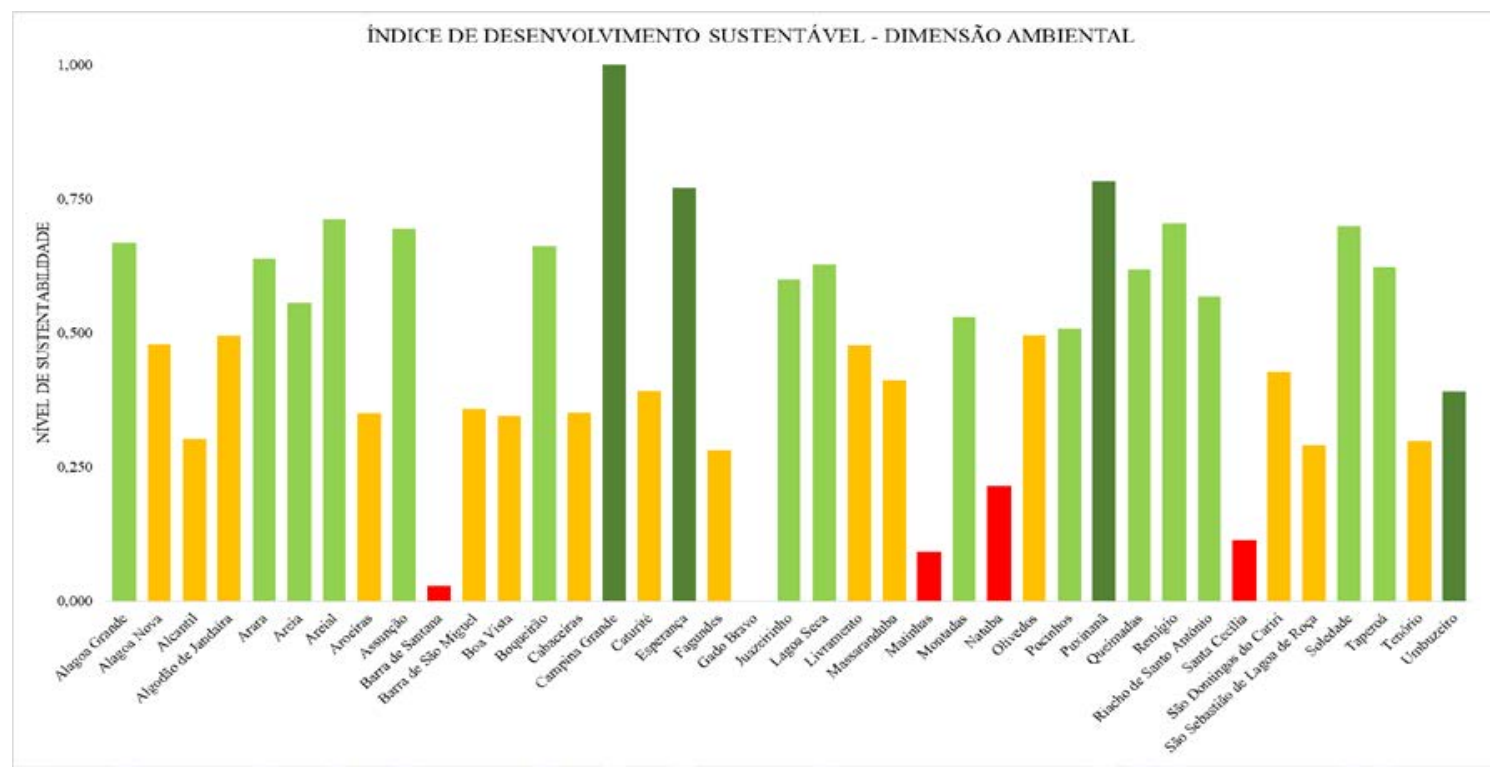

Figura 4. Índice de desenvolvimento sustentável - dimensão ambiental.

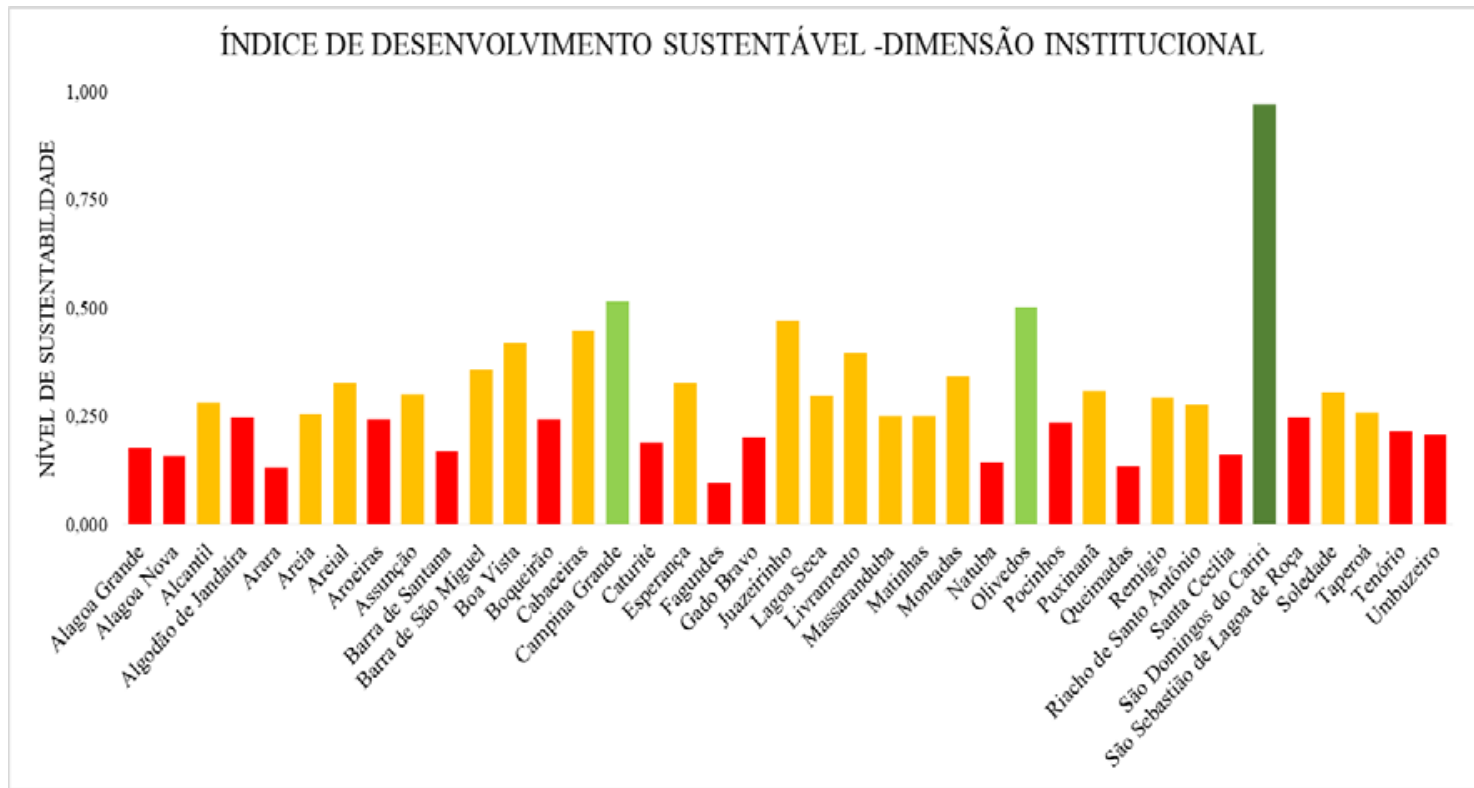

Figura 5. Índice de desenvolvimento sustentável - dimensão institucional.

Os índices de desenvolvimento sustentável para dimensão demográfica por município estão na Figura 6. Contatou-se que cerca de 56\% dos municípios estão com nível de sustentabilidade aceitável. Aproximadamente 36\% dos municípios estão em uma situação ideal. Os Municípios de Arara e Areial estão em uma situação de alerta e Campina Grande está numa situação crítica. Os dados revelaram uma escolha no momento do estabelecimento das relações entre os indicadores e a sustentabilidade. Considerou-se que a densidade demográfica, indicador que está formando o índice, tem uma relação negativa com a sustentabilidade, pois quanto mais densas as regiões mais pressões sociais, 
ambientais e econômicas acontecem, sendo assim, os municípios com mais densidade são menos sustentáveis nesse indicador.

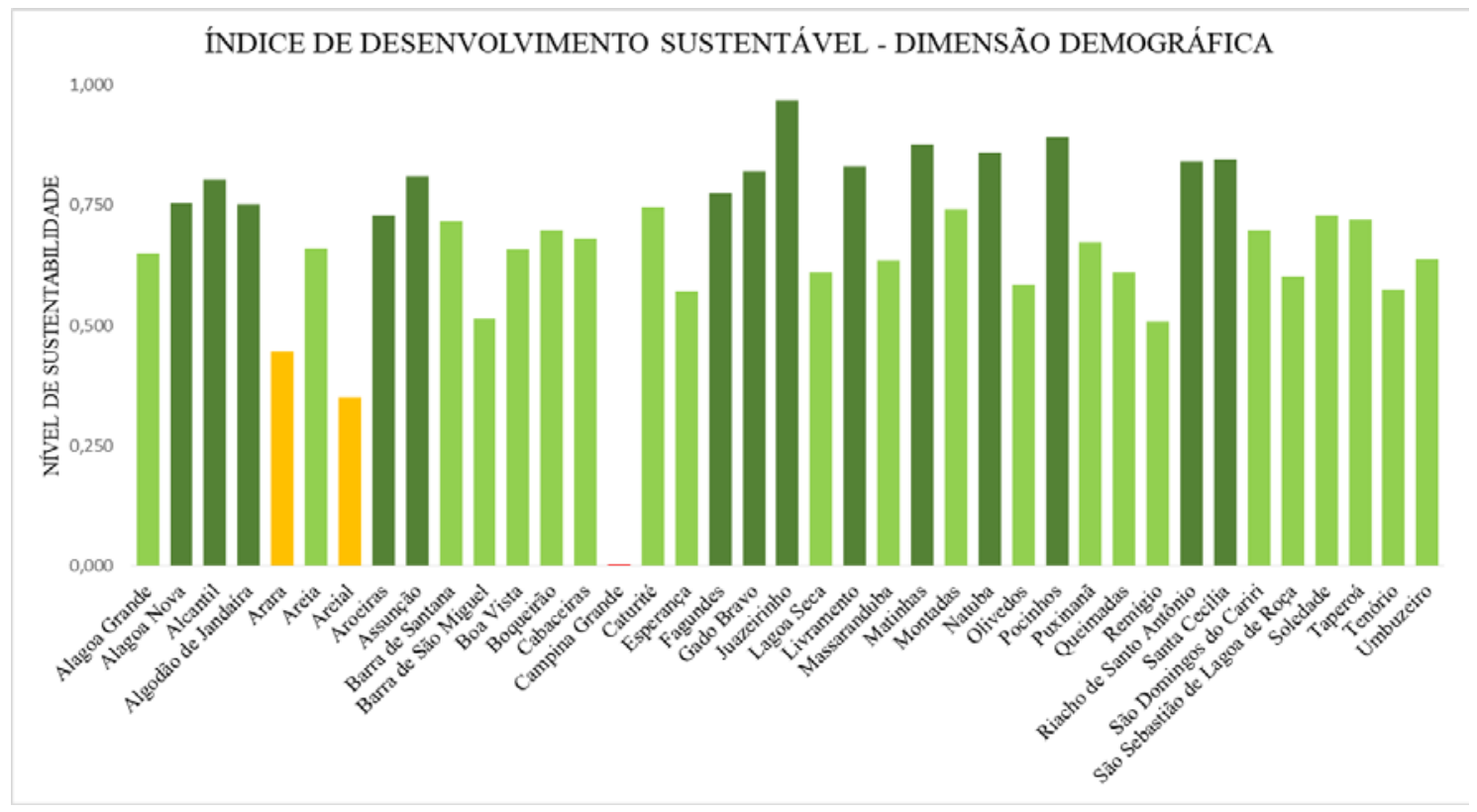

Figura 6. Índice de desenvolvimento sustentável - dimensão demográfica.

Os índices de desenvolvimento sustentável para a dimensão cultural por município estão na Figura 7. Os índices demonstram uma situação de distanciamento do desenvolvimento sustentável em relação a dimensão cultural. Isso porque cerca de $79 \%$ dos municípios estão em situação crítica. Aproximadamente $18 \%$ estão em situação de alerta e apenas Campina Grande está numa situação ideal. Os dados revelam precariedade de equipamentos culturais nos municípios que compõem a Terceira Região Geoadministrativa da Paraíba. Os aspectos culturais de uma sociedade são importantes para o desenvolvimento sustentável.

Depois dos cálculos dos índices por dimensão do desenvolvimento sustentável, resolveu-se agregá-los num único índice por município. Esses índices agregados estão presentes na Figura 8.

Com isso, constatou-se que o nível de sustentabilidade da maioria dos municípios paraibanos que estão na terceira Região Geoadmistrativa é de alerta (aproximadamente 90\%). Os Municípios de Barra de Santana, Gado Bravo e Santa Cecília estão em um nível crítico e Campina Grande está num nível aceitável. Considerando o índice de desenvolvimento sustentável agregado (Figura 8), podemos considerar que os municípios que formam a Terceira Região Geoadministrativa da Paraíba ainda estão distantes de um desenvolvimento sustentável e de uma situação de sustentabilidade. Nesse sentido, são necessárias políticas públicas e investimentos em áreas como educação, saúde, economia, meio ambiente, cultura, institucionalidade, entre outros. 


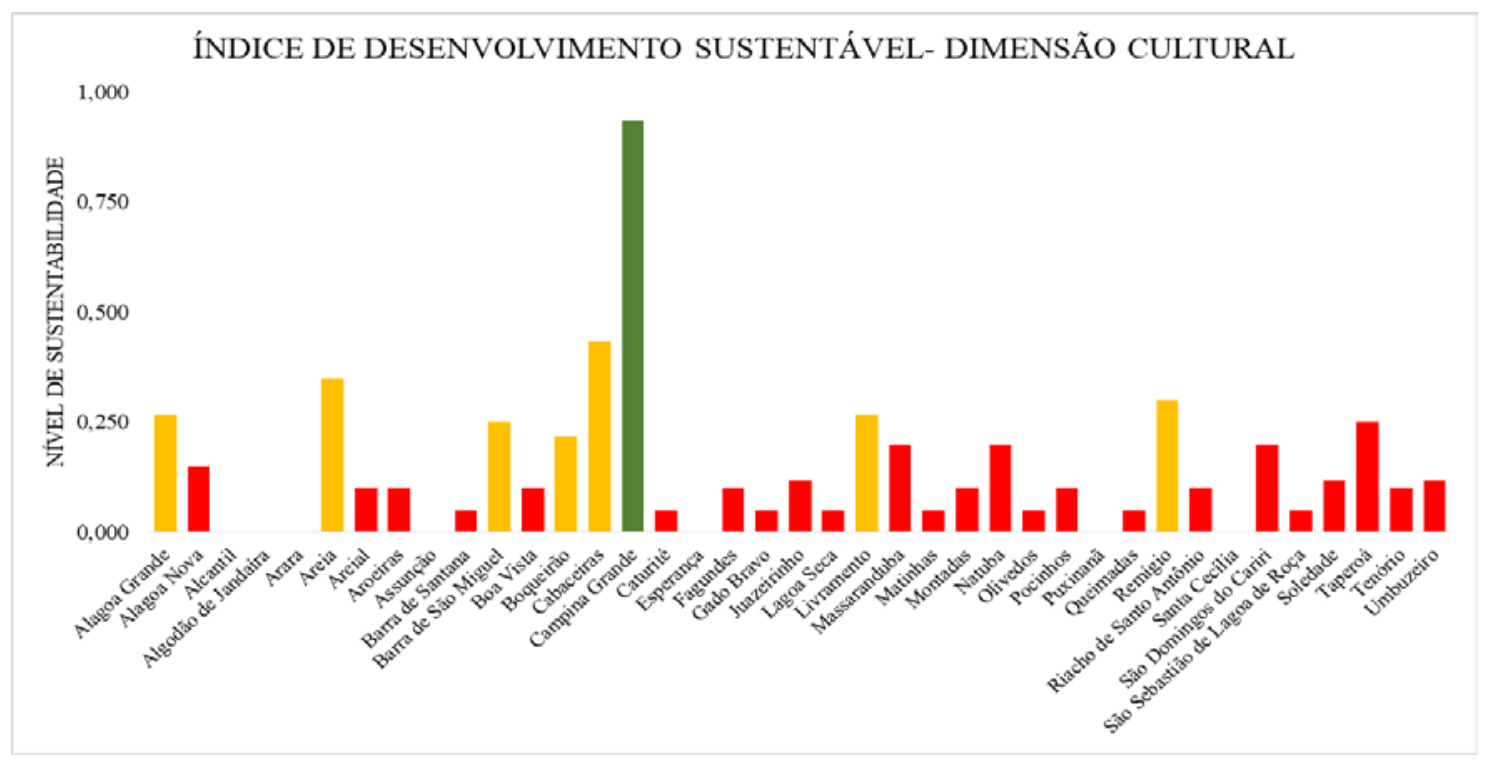

Figura 7. Índice de desenvolvimento sustentável - dimensão cultural.

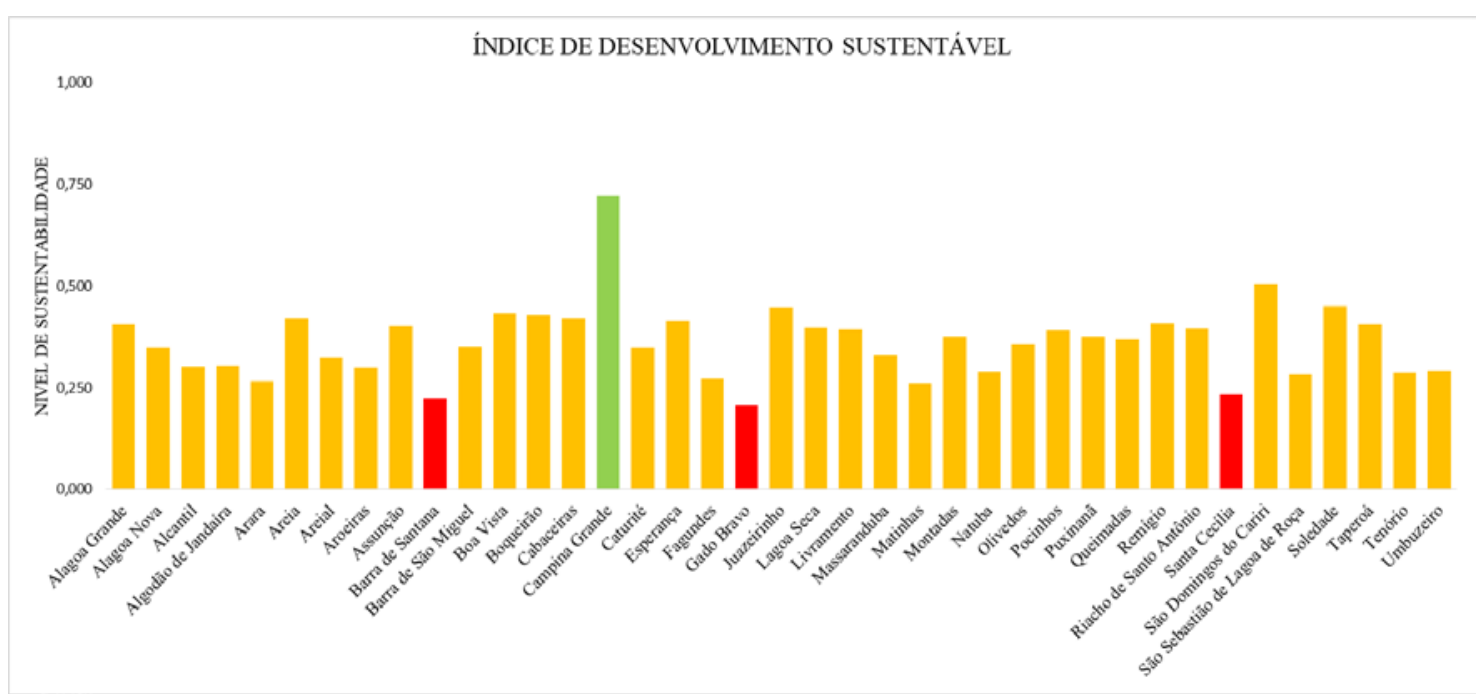

Figura 8. Índice de desenvolvimento sustentável.

\section{Conclusões}

Promover o desenvolvimento sustentável não é um processo simples, diversos aspectos estão envolvidos nele. $\mathrm{E}$ um dos fatores que contribuem para isso é a dificuldade de se equilibrarem fatores sociais, ambientais e econômicos. Diante disso, são necessárias métricas que possibilitem analisar se um sistema está ou não na direção da sustentabilidade. Assim, os indicadores e índices são importantes ferramentas que podem auxiliar esse processo. Para tanto, são necessários adequação dos indicadores a realidade que se quer analisar e rigor metodológico na construção dos sistemas de indicadores.

O Brasil é conhecido por ser um país de grandes desigualdades sociais e econômicas, e a região nordeste é especialmente afetada por essas desigualdades. Diante disso, resolveu-se analisar o nível de sustentabilidade dos municípios que compõem a 
terceira Região Geoadministrativa da Paraíba. Para tanto, optou-se pela realização de um estudo quantitativo, caracterizado como um levantamento, que se utilizou de dados secundários obtidos em pesquisa documental. Os indicadores escolhidos para análise foram propostos por Martins e Cândido (2008) e Silva et al. (2018).

Os resultados encontrados demonstraram o seguinte: na dimensão econômica, a maioria dos municípios se encontra em um nível crítico de sustentabilidade. Pode-se perceber que há uma economia pouco desenvolvida nesses municípios. Na dimensão social, a maioria dos municípios encontra-se em nível de alerta de sustentabilidade. Nesse sentido, entende-se que mais políticas de enfrentamento de desigualdades sociais são necessárias. Na dimensão ambiental, encontrou-se que a maioria dos municípios estão ou no nível aceitável ou no nível de alerta.

$\mathrm{Na}$ dimensão institucional, a maior parcela está no nível de alerta para a sustentabilidade. Na dimensão demográfica, a maioria está em situação aceitável e isso se deu pois entendeu-se que o indicador de densidade demográfica tem uma relação negativa com a sustentabilidade, já que uma maior pressão demográfica também provoca pressões econômicas, sociais e ambientais. Na dimensão cultural, a maioria dos municípios está em situação crítica. Isso é um problema para a sociedade e, consequentemente, para o desenvolvimento sustentável. Depois dos cálculos por dimensões, resolveu-se calcular um índice agregado de desenvolvimento sustentável para cada um dos municípios que revelou que aproximadamente $90 \%$ dos municípios estão numa situação de alerta.

Diante dos resultados obtidos, considera-se que a maioria dos municípios que formam a terceira região Geoadministrativa da Paraíba necessita avançar em muitos aspectos na busca pelo desenvolvimento sustentável. Assim, são necessários investimentos e políticas públicas que melhorem os aspectos sociais, econômicos, ambientais, demográficos, institucionais e culturais desses municípios. Como limitações desse estudo aponta-se o seguinte: não foi utilizado um método que pudesse ponderar os indicadores de acordo com sua importância para a sustentabilidade para a formação dos índices. Também não foi utilizado um método para ponderar os índices de acordo com sua relevância para a sustentabilidade para a formação do índice de desenvolvimento sustentável agregado. Além disso, não houve participação de membros das comunidades analisadas na fase de escolha dos indicadores. No entanto, os resultados são compatíveis com outros estudos já realizados em municípios. Como estudos futuros, sugerem-se a realização de um estudo longitudinal e a análise dos demais municípios paraibanos.

\section{Conflito de interesses}

Os autores declaram não haver conflito de interesses.

\section{Referências}

Abramovay, R. Muito além da economia verde. São Paulo: Abril, 2012.

AESA - Agência Executiva de Gestão das Águas. 2018. Disponível em: <http://www.aesa.pb.gov.br/aesa-website/>. Acesso em: 05 nov. 2019.

Becker, W.; Saisana, M.; Paruolo, P.; Vandecasteele, I. Weights and importance in composite indicators: Closing the gap. Ecological Indicators, v. 80, p. 12-22, 2017. https://doi.org/10.1016/j.ecolind.2017.03.056

Bengtsson, M.; Alfredsson, E.; Cohen, M.; Lorek, S.; Schroeder, P. Transforming systems of consumption and production for achieving the sustainable development goals: Moving beyond efficiency. Sustainability Science, v. 13, n. 6, p.1533-1547, 2018. https://doi.org/10.1007/s11625-018-0582-1 
Brundtland, G. H. Our common future. Oxford: Oxford University Press, 1987.

Candido, G. A.; Martins, M. F.; Barbosa, A. P. A. Centro de Desenvolvimento Regional (CDR): uma aplicação na região polarizada pelo Município de Campina Grande (PB). Parcerias Estratégicas, v. 22, n. 45, p. 39-58, 2018.

Carvalho, P. G. M.; Barcellos, F. C. Construindo indicadores de sustentabilidade. Indicadores Econômicos FEE, v. 37, n. 1, 2009. Disponível em: $<$ https://revistas.planejamento.rs.gov.br/index.php/indicadores/article/view/2280>. Acesso em: 18 nov. 2019.

Chelli, F. M.; Ciommi, M.; Gigliarano, C. The index of sustainable economic welfare: A comparison of two Italian regions. Procedia - Social and Behavioral Sciences, v. 81, p. 443-448, 2013. https://doi.org/10.1016/j.sbspro.2013.06.457

CMMAD - Comissão Mundial sobre Meio Ambiente e Desenvolvimento. Nosso futuro comum. Rio de Janeiro: FGV, 1991.

Cornescu, V.; Adam, R. Considerations regarding the role of indicators used in the analysis and assessment of sustainable development in the EU. Procedia Economics and Finance, v. 8, n. 14, p. 10-16, 2014. https://doi.org/10.1016/S2212-5671(14)00056-2

Creswell, J. W. Projeto de pesquisa: métodos qualitativo, quantitativo e misto. Porto Alegre: Artmed, 2010.

Du Pisani, J. A. Sustainable development: Historical roots of the concept. Environmental Sciences, v. 3, n. 2, p. 83-96, 2006. https://doi.org/10.1080/15693430600688831

Feil, A. A.; Schreiber, D. Análise da estrutura e dos critérios na elaboração de um índice de sustentabilidade. Sustentabilidade em Debate, v. 8, n. 2, p. 30-43, 2017. https://doi.org/ 10.18472/SustDeb.v8n2.2017.21516

Hopwood, B.; Mellor, M.; O'Brien, G. Sustainable development: Mapping different approaches. Sustainable Development, v. 13, n. 1, p. 38-52, 2005. https://doi.org/ $10.1002 /$ sd.244

IBGE - Instituto Brasileiro de Geografia e Estatística. Censo demográfico. 2010. Disponível em: <https://sidra.ibge.gov.br/>. Acesso em: 04 nov. 2019.

IBGE - Instituto Brasileiro de Geografia e Estatística. Cidades@, 2016. Disponível em: <https://cidades.ibge.gov.br/>. Acesso em: 04 nov. 2019.

IBGE - Instituto Brasileiro de Geografia e Estatística. Cidades@. 2017. Disponível em: <https://cidades.ibge.gov.br/>. Acesso em: 04 nov. 2019.

IBGE - Instituto Brasileiro de Geografia e Estatística. Cidades@. 2018. Disponível em: <https://cidades.ibge.gov.br/>. Acesso em: 04 nov. 2019.

IBGE - Instituto Brasileiro de Geografia e Estatística. Cidades@. 2019. Disponível em: <https://cidades.ibge.gov.br/>. Acesso em: 04 nov. 2019.

INPE - Instituto Nacional de Pesquisas Espaciais. Portal do Programa Queimadas. 2018. Disponível em: <https://queimadas.dgi.inpe.br/queimadas/portal>. Acesso em: 11 nov. 2019.

IUCN - International Union for Conservation of Nature; WWF - World Wildlife Fund. World conservation strategy: Living resource conservation for sustainable development. Gland: UICN/WWF, 1980. 
Kelley, J. G.; Simmons, B. A. Politics by number: Indicators as social pressure in international relations. American Journal of Political Science, v. 59, n. 1, p. 55-70, 2015. https://doi.org/10.1111/ajps.12119

Martins, M. F.; Cândido, G. A. Índice de desenvolvimento sustentável para municípios. João Pessoa: SEBRAE, 2008.

Martins, M. F.; Cândido, G. A. Índices de desenvolvimento sustentável para localidades: uma proposta metodológica de construção e análise. Revista de Gestão Social e Ambiental, v. 6, n. 1, p. 3-19, 2012. https://doi.org/10.5773/rgsa.v6i1.229

MDR - Ministério do Desenvolvimento Regional. 2017. Disponível em: <https://www.gov.br/mdr/pt-br>. Acesso em: 05 nov. 2019.

Meadows, D. H.; Meadows, D. L.; Randers, J.; Behrens, W. W. The limits to growth: A report for the Club of Rome's Project on the predicament of mankind. New York: Universe Books, 1972.

Ministério da Cidadania. Bolsa Família e Cadastro Único, 2019. Disponível em: <https://aplicacoes.mds.gov.br/sagirmps/bolsafamilia/index.html>. Acesso em: 05 nov. 2019.

Ministério da Economia. 2018. Disponível em: <https://www.gov.br/economia/pt-br>. Acesso em: 05 nov. 2019.

Ministério da Economia. 2019. Disponível em: <https://www.gov.br/economia/pt-br>. Acesso em: 05 nov. 2019.

Mitcham, C. The concept of sustainable development: Its origins and ambivalence. Technology in Society, v. 17, n. 3, p. 311-326, 1995. https://doi.org/10.1016/0160791X(95)00008-F

Moldan, B.; Janoušková, S.; Hák, T. How to understand and measure environmental sustainability: Indicators and targets. Ecological Indicators, v. 17, p. 4-13, 2012. https://doi.org/10.1016/j.ecolind.2011.04.033

MS - Ministério da Saúde. Sistema de Informações do Programa Nacional de Imunizações. 2018. Disponível em: <http://sipni.datasus.gov.br/si-pni-web/faces/inicio.jsf>. Acesso em: 06 nov. 2019.

MS - Ministério da Saúde. Portal da Saúde. 2010. Disponível em: <http://www2.datasus.gov.br/DATASUS/index.php>. Acesso em: 05 nov. 2019.

MS - Ministério da Saúde. Portal da Saúde. 2017. Disponível em: <http://www2.datasus.gov.br/DATASUS/index.php>. Acesso em: 05 nov. 2019.

MS - Ministério da Saúde. Portal da Saúde. 2019. Disponível em: <http://www2.datasus.gov.br/DATASUS/index.php>. Acesso em: 05 nov. 2019.

PNUD - Programa das Nações Unidas para o Desenvolvimento. Atlas do Desenvolvimento Humano no Brasil. 2010. Disponível em: <http://www.atlasbrasil.org.br/>. Acesso em: 18 nov. 2019.

Prescott-Allen, R. Barometer of sustainability. Gland: UICN, 1995.

Siche, R.; Agostinho, F.; Ortega, E.; Romeiro, A. Índices versus indicadores: precisões conceituais na discussão da sustentabilidade de países. Ambiente \& Sociedade, v. 10, p. 137-148, 2007. https://doi.org/10.1590/S1414-753X2007000200009 
Silva, J. F. B. A.; Rebouças, S. M. D. P.; Abreu, M. C. S.; Ribeiro, M. C. R. Construção de um índice de desenvolvimento sustentável e análise espacial das desigualdades nos municípios cearenses. Revista de Administração Pública, v. 52, n. 1, p. 149-168, 2018. https://doi.org/10.1590/0034-7612163114

Singh, R. K.; Murty, H. R.; Gupta, S. K.; Dikshit, A. K. An overview of sustainability assessment methodologies. Ecological Indicators, v. 9, n. 2, p. 189-212, 2009. https://doi.org/10.1016/j.ecolind.2008.05.011

Sotomayor, 0. Growth with reduction in poverty and inequality: Did Brazil show the way? The Journal of Economic Inequality, v. 17, p. 521-541, 2019. https://doi.org/10.1007/ s10888-019-09418-6

Talberth, J.; Cobb, C.; Slattery, N. The genuine progress indicator 2006. Oakland, CA: Redefining Progress, 2007.

TCPB - Tribunal de Contas do Estado da Paraíba. SAGRES online. 2018. Disponível em: <https://tce.pb.gov.br/sagres-online>. Acesso em: 06 nov. 2019.

TSE - Tribunal Superior Eleitoral. Estatísticas do Eleitorado. 2018. Disponível em: <https://www.tse.jus.br/eleitor/estatisticas-de-eleitorado/eleitorado>. Acesso em: 06 nov. 2019.

UNDP - United Nations Development Programme. Human development report. Oxford: Oxford University Press, 1995. Disponível em: <http://hdr.undp.org/sites/default/files/ reports/256/hdr_1995_en_complete_nostats.pdf>. Acesso em: 04 nov. 2019.

van Bellen, H. M. As dimensões do desenvolvimento: um estudo exploratório sob a perspectiva das ferramentas de avaliação. Revista de Ciências da Administração, v. 12, n. 27, p. 143-168, 2010.

Wackernagel, M.; Rees, W. Our ecological footprint: Reducing human impact on the Earth 9. ed. Gabriola Island: New Society Publishers, 1998.

Wojewnik-Filipkowska, A.; Węgrzyn, J. Understanding of public-private partnership stakeholders as a condition of sustainable development. Sustainability, v. 11, n. 4, 1194, 2019. https://doi.org/10.3390/su11041194

Informação da Licença: Este é um artigo Open Access distribuído sob os termos da Licença Creative Commons Attribution, que permite uso irrestrito, distribuição e reprodução em qualquer meio, desde que a obra original seja devidamente citada. 